\title{
Tissue Distribution of Pseudomonas plecoglossicida in Experimentally Infected Ayu Plecoglossus altivelis Studied by Real-time Quantitative PCR
}

\author{
Sukenda* and Hisatsugu Wakabayashi \\ Department of Aquatic Bioscience, Graduate School of Agricultural and Life Sciences, The University of \\ Tokyo, Yayoi 1-1-1, Bunkyo, Tokyo 113-8657, Japan
}

(Received August 18, 2000)

\begin{abstract}
Distribution of Pseudomonas plecoglossicida in tissues of ayu (Plecoglossus altivelis) challenged by immersion was studied by real-time quantitative polymerase chain reaction (Q-PCR). Fish were immersed in $10^{7} \mathrm{CFU} / \mathrm{mL}$ of $P$. plecoglossicida suspension for $15 \mathrm{~min}$. The fish were sampled at 1, 3, 6, 12, 24, 48, $72 \mathrm{~h}$ post-infection (p.i.) and the skin, gills, liver, spleen, kidney and blood were tested by Q-PCR. The skin and gills are likely to be portals of entry for the bacterium since $P$. plecoglossicida was found as early as 1 and $3 \mathrm{~h}$ p.i., respectively. The bacteria became concentrated in the liver, spleen and kidney at $6 \mathrm{~h} \mathrm{p.i.,} \mathrm{indicating} \mathrm{that} P$. plecoglossicida can successfully invade ayu within $6 \mathrm{~h}$ p.i. Septicemia occurred at $48 \mathrm{~h}$ p.i., because high concentrations of the target DNA were abruptly found in the blood of infected fish. The sensitivity of QPCR used here was slightly higher than the culture method to identify subclinically infected fish by $P$. plecoglossicida. High throughput and turnover time of this assay is useful for monitoring large number of samples and rapid detection.
\end{abstract}

Key words: Pseudomonas plecoglossicida, ayu, quantitative PCR, bacterial hemorrhagic ascites, Plecoglossus altivelis, portal of entry

Bacterial hemorrhagic ascites $(\mathrm{BHA})$ has emerged as a new disease causing mass mortality among cultured ayu (Plecoglossus altivelis) (Wakabayashi et al., 1996). The spread of the disease has been reported from fish farms throughout Japan since 1994. The causative agent was recently given the name Pseudomonas plecoglossicida (Nishimori et al., 2000). The disease is characterized by bloody ascites with a large number of bacteria in the blood and internal organs of affected fish. However, no information is presently available with respect to the mechanism of infection of this bacterium. An initial research on kinetics of $P$. plecoglossicida infection in ayu was performed by Sukenda and Wakabayashi (1999). P. plecoglossicida was recovered from the liver, spleen, kidney and blood of experimentally infected fish using a standard bacteriological culture method. However, this method is very difficult for large number of samples and rapid detection. An alternative method to determine the kinetics of $P$. plecoglossicida in ayu is needed.

\footnotetext{
* Corresponding author

E-mail: aa87078@mail.ecc.u-tokyo.ac.jp
}

We have addressed these issues by developing a real-time quantitative TaqMan PCR assay (Heid et al., 1996; Gibson et al., 1996) for measuring copy number of $P$. plecoglossicida DNA in the host tissue. This method measures the accumulation of PCR product with a fluorogenic probe and by real time laser scanning in a 96-well plate. The assay has been successfully used to quantify small amount of fetal DNA in maternal plasma and serum (Lo et al., 1998), simian immunodeficiency virus (SIV) RNA in plasma (Suryanarayana et al., 1998) and detection of Ralstonia solanacearum, the causative agent of potato rot disease (Weller et al., 2000). We used this technique to investigate tissue distribution and growth of $P$. plecoglossicida during experimental infection in ayu. The localization of the bacterium in tissues might provide some answers concerning the natural mode of entry of the pathogen, and its infectious processes inside the fish.

\section{Materials and Methods}

Fish and bacteria

Ayu (Plecoglossus altivelis) weighing about $7 \mathrm{~g}$ 
were obtained from Yamanashi Prefectural Fisheries Technology Center and maintained in a tank supplied with dechlorinated tap water at $24^{\circ} \mathrm{C}$ and fed daily. Fish were not fed for $24 \mathrm{~h}$ before experiments.

P. plecoglossicida FPC $951^{\top}$ (= ATCC $700383^{\top}$ ) (Nishimori et al., 2000) was used in this study. The strain was kept frozen at $-80^{\circ} \mathrm{C}$ in tryptic soy broth (TSB) (Nissui) containing 10\% (v/v) glycerol. Cultures were used after growing for $24 \mathrm{~h}$ at $25^{\circ} \mathrm{C}$ in TSB. The bacterial cells were harvested from culture and washed with physiological saline and resuspended in autoclaved dechlorinated tap water at density of $10^{7} \mathrm{CFU} / \mathrm{mL}$.

Distribution of P. plecoglossicida in experimentally infected ayu

Ayu were challenged by immersion in $10^{7} \mathrm{CFU} / \mathrm{mL}$ of $P$. plecoglossicida suspension for $15 \mathrm{~min}$, and then distributed into 7 tanks (12-L) each with 5 fish. The fish were sampled at $1,3,6,12,24,48,72 \mathrm{~h}$ post infection (p.i). Fish were anaesthetized with 250 ppm of 2phenoxyethanol and then bled at the caudal vein with non heparinized syringe. Skin scrapings, gills, liver, spleen, and kidney were collected and frozen at $-80^{\circ} \mathrm{C}$ until processed for DNA extractions as described below.

\section{Sample preparations for PCR}

The tissue samples were thawed, weighed, homogenized $(10 \% \mathrm{w} / \mathrm{v})$ in PBS $(0.8 \% \mathrm{w} / \mathrm{v} \mathrm{NaCl}, 7 \mathrm{mM}$ $\mathrm{K}_{2} \mathrm{HPO}_{4}, 2.5 \mathrm{mM} \mathrm{KH}_{2} \mathrm{PO}_{4}, \mathrm{pH} 7.4$ ) containing $0.05 \% \mathrm{v} / \mathrm{v}$ Tween 20 (PBS/T20) (Brown et al., 1994). DNA was extracted from homogenized tissue and blood using proteinase $\mathrm{K}$ tissue lysis, CTBA (hexadesyltrimethyl ammonium bromide) polysaccharides extractions, and phenol chloroform DNA extractions as described by Ausubel et al. (1990). The concentration of DNA in each sample was determined spectrophotometrically at $260 \mathrm{~nm}$ and target DNA was detected by real-time quantitative PCR as described below.

\section{Development of real-time quantitative PCR}

\section{ABI Prism 7700 sequence detector system}

The design and operation of the $\mathrm{ABI}$ Prism 7700 sequence detector system have been described in detail elsewhere (Heid et al., 1996; Gibson et al., 1996). In this system, in addition to the amplification primers, as in the conventional PCR, a dual-labeled fluorogenic hybridization probe is also included (Livak et al., 1995). The probe is labeled at both ends with a reporter fluorochrome, FAM or VIC (Perkin Elmer) and a quencher fluorochrome, TAMRA. During the extention phase in PCR, the 5' to 3' exonuclease activity of the Taq DNA polymerase cleaves the reporter from the probe, thus releasing it from the quencher, resulting in an increase in the fluorescence emission at $518 \mathrm{~nm}$.

The fluorescence data were expressed as $\triangle R n$, where this value represents the change in reporter dye fluorescence, subtracting background fluorescence on the basis of average signal recorded for measurements obtained during the early PCR cycles (typically cycles 315 , when cleaved probe is generally not yet detectable) and normalizing on the basis of the peak signal for nonconjugated third dye (rhodamine; ROX), included at a constant concentration in the reaction buffer as a passive optical path control whose fluorescence in not expected to change significantly through amplification. $\triangle R n$ values can be plotted as a function of amplification cycles. The first cycle during which an above background fluorescent signal is measured is defined as the threshold cycle $\left(C_{T}\right)$. A plot of $C_{T}$ versus input template copy number provides a standard curve with body dynamic range, owing to the kinetic nature of the measurements.

\section{PCR primer and labeled hybridization probe}

Primers and dual-labeled fluorescent TaqMan probe used are listed in Table 1. TaqMan probes were custom-synthesized by PE Applied Biosystems, and the PCR primers were synthesized by Life Technologies.

We used a 244 bp gyrB coding region derived from $P$. plecoglossicida FPC $951^{\top}$ gyrB gene sequence as a target PCR. In this Q-PCR procedure, an internal control of the same size and containing identical priming ends as that of target DNA but with a foreign internal sequences were generated. Both the internal control and target DNA contained 26 bp of unique unshared sequences. By using a standard molecular protocol (Sambrook et al., 1989), both target and internal control sequences were ligated into PT7blue T-vector (Takara) and cloned to Escherichia coli JM109 cells (Takara), named pTGT and pISD, respectively. The recombinant plasmid was purified with Plasmid Mini Kit (Qiagen), quantified spectrophotometrically and stored at $-20^{\circ} \mathrm{C}$

Table 1. Primers and probes used in this assay

\begin{tabular}{clcc}
\hline Primers or probes & \multicolumn{1}{c}{ Sequences (5'-3') } & Length (nt) & Dye \\
\hline GBPA-F & 5'-CCTGCTGAAGGACGAGCGTTCG-3' & 22 & \\
GBPA-R & 5'-AACCAGGTGAGTACCACCGTCG-3' & 22 & \\
& & & FAM \\
TGT-P & 5'-(FAM)AGATGGCGTGGGCGTTGAAGTAGCGC(TAMRA)-3' & 26 & VIC \\
ISD-P & 5'-(VIC)CCTTCACCACCACGGCCGAGCGTGAG(TAMRA)-3' & 26 & \\
\hline
\end{tabular}


until used.

\section{Optimization of TaqMan PCR}

TaqMan amplification reactions were set up in a reaction volume of $20 \mu \mathrm{L}$ using components supplied in a TaqMan PCR Core reagent Kit (Perkin-Elmer). The mixtures were used to generate two sets of tubes. Each reaction contained $2 \mu \mathrm{L}$ of $10 \mathrm{x}$ buffer $\mathrm{A}, 1 \mu \mathrm{M}$ of each amplification primer, $250 \mathrm{nM}$ of the corresponding TaqMan probe, $5 \mathrm{mM} \mathrm{MgCl}_{2}, 200 \mu \mathrm{M}$ each dATP, dCTP, and dGTP, $400 \mu \mathrm{M}$ dUTP, $0.5 \mathrm{U}$ AmpliTaq Gold, and 0.2 $\mathrm{U}$ AmpErase uracil N-glycosylase. The target hybridization probe was added to the first set of tubes and the internal control probe was added to the second set of tubes. We used $1 \mu \mathrm{L}$ of extracted tissue DNA for amplification. The exact amount used was recorded, for subsequent concentration calculations. DNA amplifications were carried out in 96-well arrays of optical-grade thin well PCR tubes where the first and second set of tubes each occupy one half of wells. Both sets of tubes were subjected to PCR amplification using a sequences detector with the following profile: 1 cycle $\left(50^{\circ} \mathrm{C}\right.$ for 2 min), 1 cycle $\left(95^{\circ} \mathrm{C}\right.$ for $\left.10 \mathrm{~min}\right), 50$ cycle $\left(95^{\circ} \mathrm{C}\right.$ for $15 \mathrm{~s}$ and $68^{\circ} \mathrm{C}$ for $1 \mathrm{~min}$ ). A standard curve generated from ten-fold dilutions in milliQ of target gene in purified PTGT, ranging from $10^{6}$ to 10 copy target DNA, was run in parallel and in duplicate with each analysis. A known amount of internal control in purified pISD $\left(10^{2}\right.$ copy number) was added in all tubes for amplification. As the corresponding tubes in each set contained identical concentrations of target and internal control DNA, amplification for both sets of tubes were assumed to be identical. However, because the first set of tubes contained the target probe, its reporter fluorescence emission was attributed entirely to internal control amplification of the target and was unaffected by the concentration of internal control. The fluorescence in tubes containing internal control probe (the second set) was attributed entirely to internal control amplification. The calculated number of copies per reactions were then normalized and expressed as copy gyrB gene per $\mu \mathrm{g}$ of starting DNA. Analyses for which individual values of duplicate amplifications were more than $10 \%$ greater or less than the average duplicate values are repeated. Samples were defined as negative if the $C_{T}$ values exceeded 50 cycles. A standard curve was constructed by plotting the ratio of the mean $\mathrm{C}_{\mathrm{T}}$ values of target and internal control against the known target copy number from 14 PCR runnings.

\section{Specificity, sensitivity and comparison of Q-PCR with} culture

In order to check the PCR primers and probe for species-specificity, $P$. plecoglossicida (FPC $951^{\top}$, FPC 941, and FPC 337), P. putida (ATCC 12633 and 17472), $P$. chlororaphis (FPC 308), $P$. fluorescens (FPC 96), $P$. aeroginosa (IAM 1514), $P$. anguilliseptica (FPC 52), $P$. piscicida (FPC 851), F. psychrophilum (FPC 828), $F$. columnare (FPC 970), V. anguillarum (FPC 346), E. tarda (FPC 801), E. ictaluri (FPC 447), A. hydrophila (IAM 12337), A. salmonicida (FPC 365), and E. coli (FPC 350) were used. DNA was extracted from these bacteria using QIAamp DNA Mini Kit (Qiagen), and QPCR was performed.

DNA of presumed negative tissue homogenates (by Q-PCR and culture) were extracted, and seeded with serial dilutions of the copy number of target DNA (ranging from 1 to $10^{3}$ ), and Q-PCR was performed.

To compare the sensitivity of PCR with that of culture method to identify bacterium in infected fish, ayu were immersed with approximately $10^{7} \mathrm{CFU} / \mathrm{mL}$ of $P$. plecoglossicida suspension for $15 \mathrm{~min}$. Any fish that died were removed and checked for internal clinical sign of BHA and for $P$. plecoglossicida by culture of kidney tissue on TSA. At $3 \mathrm{~d}$ post-infection (p.i.), the remaining fish were sacrified and checked for $P$. plecoglossicida by both culture of kidney tissue on TSA and Q-PCR of kidney tissue. The number of $P$. plecoglossicida CFU per gram of kidney tissue were determined as previous experiment (Sukenda and Wakabayashi, 1999) and Q-PCR was performed as described above.

\section{Results}

\section{Real-time quantitative PCR}

Fig. 1 shows the result of the amplifications of different concentrations of DNA target and $10^{2}$ copies of internal control. There was a linear relationship between the estimated number of target copies added to the reac-

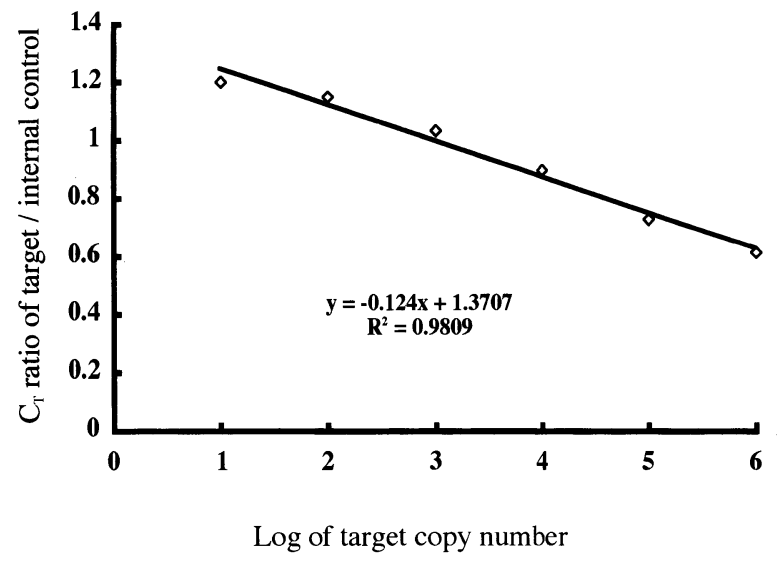

Fig. 1. Real-time quantitative PCR standard curve. Duplicate sets of tubes containing tenfold serial dilutions of target DNA co-amplified with fixed concentrations of internal control $\left(10^{2}\right.$ copies). Target of hybridization probe was added to the first set of tubes, while internal control hybridization probe was added to second set of tubes. $\mathrm{C}_{\mathrm{T}}$ ratio of target DNA and internal control are plotted against copy number of target. 
tions and $\mathrm{C}_{\mathrm{T}}$ of target and internal control ratios obtained after amplifications. The linearity was maintained for the range 10 to $10^{6}$ target copies.

Specificity, sensitivity and comparison of Q-PCR with culture

The Q-PCR assay was capable of amplifying $P$. plecoglossicida strains, but not the other bacteria. The $\mathrm{C}_{\mathrm{T}}$ values for the others exceed 50 .

DNA was extracted from presumed negative (by culture and $\mathrm{Q}-\mathrm{PCR}$ ) tissue homogenates, and seeded with DNA target ranging from 1 to $10^{3}$ copies in number. QPCR detected 10 copy number of target DNA per $\mu \mathrm{g}$ DNA background (data not shown). In addition to the use of optimized PCR conditions for the ABI Prism 7700 sequence detector system, one important observation in our study is that amplification of low levels of target requires more PCR cycles than conventional 45 cycles, so we chose 50 cycles for our assay.

Fish challenged with bacteria were sampled at $3 \mathrm{~d}$ p.i., by which time the number of dead fish was 4 of the 14 infected fish. The dead fish displayed typical symp- toms of $\mathrm{BHA}$, bloody ascites, with a large number of bacteria in the blood and internal organs following cultivation of the tissues on TSA. Some of the live-sampled fish were also positive on culture (7 of 10). DNA of kidneys from all of the culture- positive fish scored positive by $Q$ PCR. However, two of the three culture-negative fish were scored positive by $\mathrm{Q}-\mathrm{PCR}$, suggesting that the sensitivity of Q-PCR was slightly higher than the culture method (Table 2).

\section{Disributions of $\mathrm{P}$. plecoglossicida in tissues}

The localization of $P$. plecoglossicida DNA in different tissues and organs of the infected ayu are shown in Figs. 2A-F. The results showed that the target DNA was detected in the skin and gill, at early p.i. ( $1 \mathrm{~h}$ and $3 \mathrm{~h}$ p.i.), and still remained at $72 \mathrm{~h}$ p.i. In the internal organs (liver, spleen, and kidney), the target DNA was detected at $6 \mathrm{~h}$ p.i., indicating that the bacterium was already actively invading the fish. Generally, there was an increase in target DNA in the internal organs (liver, spleen and kidney) from 6 to $72 \mathrm{~h}$ p.i. (Figs. 2C-E) However, the target DNA seemed to increase more in the

Table 2. Comparison of culture and Q-PCR assay for detection of $P$. plecoglossicida in kidney tissue from live-sampled experimentally infected ayu

\begin{tabular}{ccc}
\hline $\begin{array}{c}\text { CFU of } P \text {. plecoglossicida / } \\
\text { of kidney tissue }\end{array}$ & No. of fish sampled & No. of fish positive by Q-PCR \\
\hline Not detected $\left(<4 \times 10^{2}\right)$ & 3 & 2 \\
$4 \times 10^{2}-44 \times 10^{6}$ & 4 & 4 \\
$>4 \times 10^{6}$ & 3 & 3 \\
\hline
\end{tabular}

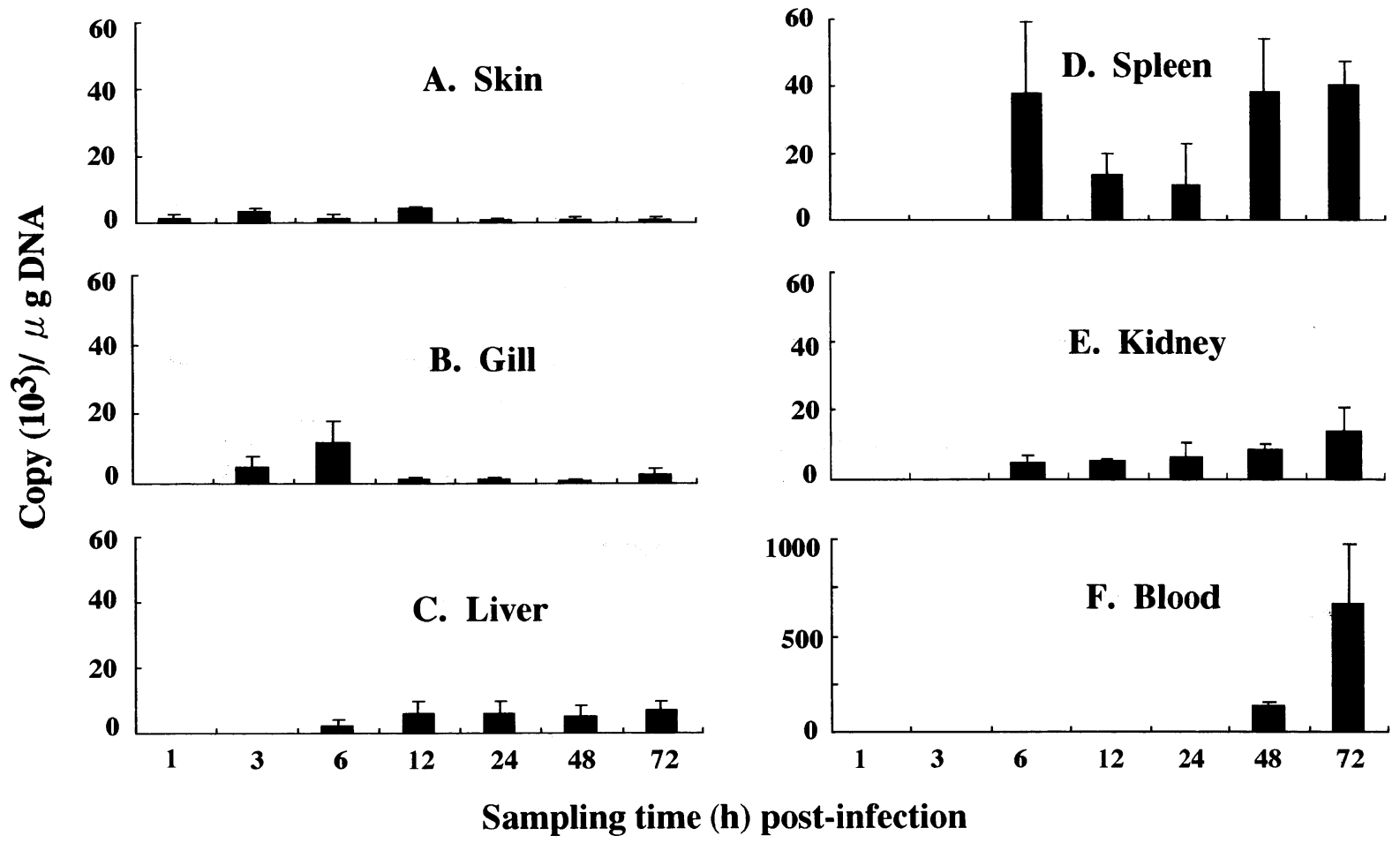

Fig. 2. Number of copies of $P$. plecoglossicida gyrB gene in different tissues of ayu at different time post-infection. 
spleen than the others. At $48 \mathrm{~h} \mathrm{p.i,} \mathrm{the} \mathrm{bacterium} \mathrm{was}$ detected in the blood with large amount, showing that septicemia occurred. Bacterial presence was detected in the blood later than other internals organs. The spleen and blood demonstrated the highest amount of bacterial production among the organs assayed.

\section{Discussion}

The initial objective of this study was to evaluate the pathogen distributions in tissue of ayu after immersed in $P$. plecoglossicida culture. In the previous assay, the distribution of $P$. plecoglossicida was determined by cultivation of homogenate host tissues on TSA (Sukenda and Wakabayashi, 1999). In the present study, we have used newly available instrumentation to develop an assay based on real-time quantitative detection of PCR product generations for sensitive and reliable quantification of bacterial DNA in infected fish tissue. The assay provides good sensitivity, high throughput and turnover time, and eliminates the need for manipulation of amplified products, which is a major potential source of contamination. The use of internal control eliminated variable results caused by potential differences of amplifications as both target and internal controls are added to the same tube. This is a great improvement over the conventional PCR assays, which have considerable risks of carryover contaminations (Kimura et al., 1999).

Analysis of kidney tissue homogenates from ayu, which are experimentally challenged with $P$. plecoglossicida, showed that real-time quantitative PCR assay was more sensitive than the culture method to identify subclinically infected fish. PCR assay identified all culture-positive samples, as well as some culturenegative samples.

In the present study, target DNA was detected as early as $1 \mathrm{~h}$ p.i. This shows that the first colonization site of the pathogen in ayu by immersion challenge is the dermal layer of the skin. Similar result have been reported for other fish-pathogenic bacteria such as Vibrio anguillarum, which also causes another serious disease of ayu (Muroga and De La Cruz, 1987). Another possibility for pathogen entry is the gills. This is supported by our finding of the target DNA in the gills at $3 \mathrm{~h}$ p.i. At $6 \mathrm{~h}$ p.i., the target DNA was detected in the internal organs (liver, spleen and kidney), indicating that $P$. plecoglossicida can invade ayu within $6 \mathrm{~h}$ p.i. The bacterium also concentrated highly in the spleen during infection. Spleen and kidney are the most active organs in the removal of foreign organisms wherein macrophages and lymphoid cells are highly concentrated (Buras et al., 1985). P. plecoglossicida is likely trapped and concentrated in the melano-macrophage centers of these organs, as already indicated in the previous report (Sukenda and Wakabayashi, 1999). $P$. plecoglossicida was first detected in the blood at $48 \mathrm{~h}$ p.i. At the same time, the number of bacteria in the liver, spleen, and kidney did not increase sharply. However, $P$. plecoglossicida DNA increased sharply in the blood. This indicated that $P$. plecoglossicida multiply in the internal organs, invaded the blood system and has the ability to proliferate rapidly in the blood. Thus suggesting that $P$. plecoglossicida is able to cause a septicemic disease. A similar finding was observed in a previous experiment where presence of $P$. plecoglossicida in the blood was detected later than in other internal organs (Sukenda and Wakabayashi, 1999).

Based on our present results and the previous findings, the pathogenesis of $P$. plecoglossicida in ayu can be described as follows. Virulent $P$. plecoglossicida cells, upon contact with host fish, first attach to the surface of the skin of the host. Non-specific antibacterial activities in the mucus soon inactivate the bacteria (Itami et al., 1986). However, some cells can penetrate into the dermal layer and proliferate if they successfully escape from the surveillance system of the host defence mechanism. After entering the blood stream they can be transported to any parts of the body. At that time, the amount of bacteria in the blood may be negligible and undetectable yet by either bacterial culture or PCR. As a result, the major organs such as the liver, spleen, and kidney are infected. The systemic infection occurred at $48 \mathrm{~h}$ p.i. where high levels of target DNA were found present in the blood and they increased rapidly over time. Increasing levels of the target DNA in the tissues of the infected ayu indicates proliferation of bacteria in the fish, which eventually would succumb to the infection.

\section{Acknowledgements}

We thank Yamanashi Prefectural Fisheries Technology Center for providing ayu for this study and also Dr. C. J. Hayward, Chungbuk National University, for reviewing the manuscript.

\section{References}

Ausubel, F. M., R. Brent, R. E. Kingston, D. D. Moore, J. G. Seidman, J. A. Smith, K. Struhl (1990): Current protocols in molecular biology. John Wiley \& Son, New York, section 2.4 .

Brown, L. L., G. K. Iwama, T. P. T. Evelyn, W. S. Nelson and R. $P$. Levine (1994): Use of the polymerase chain reaction (PCR) to detect DNA from Renibacterium salmoninarum within individual salmonid eggs. Dis. Aquat. Org., 18, 165-171.

Buras, N., L. Duek and S. Niv (1985): Reactions of fish to microorganisms in wastewater. Appl. Environ. Microbiol., 50, 989-995.

Gibson, U. E. M., C. A. Heid, and P.M. William (1996): A novel method for real-time quantitative PCR. Genome Res., 6, 995-1001. 
Heid, C. A., J. Stevens, K. J. Livak, and P. M. Williams (1996): Real time quantitative PCR. Genome Res., 6, 986-994.

Itami, T., Y. Takahashi and I. Kawahara (1986): Bacteriolytic activity in organs of ayu and its enzymatic properties. Bull. Japan. Soc. Fish. Sci., 52, 1443-1447. (In Japanese with English summary.)

Kimura, K., M. Morita, Y. Yabuta, K. Kuzushima, K. Kato, S. Kojima, T. Matsuyama, T. Morishima (1999): Quantitative analysis of Epstein-Barr virus load by using a real-time PCR assay. J. Clin. Microbiol., 37, 132-136.

Lo, Y. M. D., M. S. C. Tein, T. K. Lau, C. J. Haines, T. N. Leung, P. M. K. Poon, J. S. Wainscoat, P. J. Johnson, A. M. Z. Chang, and N.M Hjelm (1998): Quantitative analysis of fetal DNA in maternal plasma and serum: Implications for noninvasive prenatal diagnosis. Am. J. Hum. Genet., 62, 768-775.

Livak, K. J., S. J. Flood, J. Marmaro, W. Giusti, and K. Deetz (1995): Oligonucleotides with fluorescent dyes at opposite ends provide a quenched probe system useful for detecting PCR product and nucleic acid hybridization. PCR Meth. Appl., 4, 357-362.

Muroga, K. and M.C. De La Cruz (1987): Fate and locations of Vibrio anguillarum in tissue of artificially infected ayu (Plecoglossus altivelis). Fish Pathol., 22, 99-103.

Nishimori, E., K. Kita-Tsukamoto and H. Wakabayashi (2000):
Pseudomonas plecoglossicida sp. nov., the causative agent of bacterial haemorrhagic ascites of ayu, Plecoglossus altivelis. Int. J. Syst. Evol. Microbiol., 50, 83-89.

Sambrook, J., E. F. Fritsch, and T. Maniatis (1989): Molecular Cloning : a Laboratory Manual, 2nd ed. Cold Spring Harbor Laboratory Press. Cold Spring Harbor, New York, section 1.

Sukenda and H. Wakabayashi (1999): Immersion immunization of ayu (Plecoglossus altivelis) with Pseudomonas plecoglossicida bacterin. Fish Pathol., 34, 163-164.

Suryanarayana, K., T. A. Wiltrout, G. M. Vasquez, V. M. Hirsch, and J. D. Lifson (1998): Plasma SIV viral load determinations by real-time quantifications of product generation in reverse transcriptase-polymerase chain reaction. Aids Res. Hum. Retro., 14, 183-189.

Wakabayashi, H., K. Sawada, K. Ninomiya, E. Nishimori (1996): Bacterial hemorrhagic ascites of ayu caused by Pseudomonas sp., Fish Pathol., 31, 221-227. (In Japanese with English summary.)

Weller, S. A., J. G. Elphinstone, N. C. Smith, N. Boonham, and D. E. Stead (2000): Detection of Ralstonia solanacearum strain with a quantitative, multiplex, real-time, fluorogenic PCR (TaqMan) assay. Appl. Environ. Microbiol., 66, 2853-2858. 